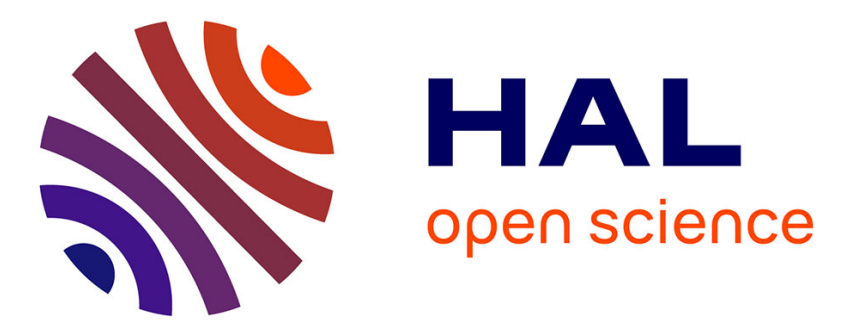

\title{
Legitimar la falsificación: la autoridad del rey y la autoridad del escribano(en torno a Pero Marín y algunos textos de Silos)
}

Amaia Arizaleta

\section{- To cite this version: \\ Amaia Arizaleta. Legitimar la falsificación: la autoridad del rey y la autoridad del escribano(en torno a Pero Marín y algunos textos de Silos). Cahiers d'Etudes Hispaniques Médiévales, 2006, 29, pp.453-468. halshs-00169176}

\section{HAL Id: halshs-00169176 \\ https://shs.hal.science/halshs-00169176}

Submitted on 1 Sep 2007

HAL is a multi-disciplinary open access archive for the deposit and dissemination of scientific research documents, whether they are published or not. The documents may come from teaching and research institutions in France or abroad, or from public or private research centers.
L'archive ouverte pluridisciplinaire HAL, est destinée au dépôt et à la diffusion de documents scientifiques de niveau recherche, publiés ou non, émanant des établissements d'enseignement et de recherche français ou étrangers, des laboratoires publics ou privés. 


\title{
Legitimar la falsificación: \\ la autoridad del rey y la autoridad del escribano (en torno a Pero Marín y algunos textos de Silos)*
}

Para Julio Escalona. Para Miguel Vivancos

$\cos 80$

\author{
lo más posible es que las cosas pasaran \\ de la manera en que parece que pasaron, \\ pero no que no puedan haber pasado de otra manera. \\ Lorenzo Silva, El lejano país de los estanques.
}

Me propongo en estas páginas estudiar las circunstancias de elaboración de tres textos - un relato hagiográfico y dos privilegios reales - compuestos en el monasterio de Santo Domingo de Silos en la segunda mitad del siglo XIII. De la autenticidad de dos de ellos no parece caber duda; es posible que el tercero sea un documento espurio. Naturalmente, habré de interesarme por los autores de dichos textos; quede claro sin embargo que no pretendo aquí entregarme al peligroso ejercicio de la identificación de individuos, sino que busco enumerar las posibilidades de escritura y de falsificación 'normativa' de esos textos silenses. Este estudio sólo

\footnotetext{
*. Este trabajo, inicialmente concebido como apostilla a mi « La memoria del monarca: Alfonso X, testigo de Pero Marín (Miraculos romançados, 4) » (en prensa para Cahiers d'Etudes Médiévales Hispaniques, 2006), aparece con anterioridad a ese primer artículo. A fin de conservar la necesaria coherencia entre ambos trabajos, me limito aquí a evocar cuestiones relacionadas con la autoría de los textos seleccionados, sin abordar su contexto histórico o funcionamiento narrativo. Para estos aspectos, véase en su momento mi «La memoria del monarca» y corríjase (o complétese) con los trabajos de Escalona (2003) y de Escalona, Azcárate, Larrañaga (2001).
} 
propondría un ejemplo, uno más, de la alianza entre la monarquía y los señores del escrito, y por tanto de la eficacia y versatilidad de la escritura como instrumento de legitimación, si no fuera por la demora con que he preferido tratar las probabilidades de autoría de esos tres textos, sus etapas de construcción, y las formas y funciones de sus respectivas reescrituras, con el fin de intentar aproximarme a la empresa de falseamiento levantada en Silos en pro del monasterio, en el último cuarto del XIII. ${ }^{1}$

\section{EL RELATO HAGIOGRAFICO}

De los 91 textos que componen la obra conocida bajo el título de Miraculos romançados (como saco Santo Domingo los cativos de captividad), ${ }^{2}$ el situado en el cuarto lugar de la colección es el que mayor interés ha despertado entre los especialistas de la edad media hispánica. En él se cuenta «como aparesçio santo Domingo en vision al rey don Alffonso enel palacio dela enfermeria». ${ }^{3}$ Ese rey beneficiario de uno de los milagros obrados por santo Domingo de Silos no es otro que Alfonso X de Castilla y León. La atención de los estudiosos se ha centrado en la presencia en este texto del soberano castellano, ${ }^{4}$ y se ha dado generalmente por sentado que su autoría, como la del resto de la colección, correspondía al monje de Silos Pero Marín. ${ }^{5}$

\footnotetext{
1. Para todo lo que sigue, es evidente mi deuda para con los trabajos de Julio Escalona, que su autor me ha comunicado generosamente. He de señalar que todo lo referente a los privilegios reales que aquí se tratan se fundamenta en los análisis de este investigador y de sus compañeros (véase supra), así como en las reflexiones de las que el propio Julio Escalona ha tenido a bien hacerme partícipe. Ello justifica de alguna manera el que mi trabajo privilegie las cuestiones relacionadas con el relato hagiográfico frente a las relativas a los privilegios, mejor conocidas por los especialistas citados. Los errores de apreciación, por supuesto, son exclusivamente míos.

${ }^{2}$. Empleo la edición paleográfica de Anton (1988), que sigue esencialmente el texto del manuscrito S, el más antiguo de los conservados. Resuelvo las abreviaturas, pero no regularizo grafías ni modernizo la puntuación.

3 . Anton (1988), p. 43-48, p. 43.

4. «Valiosa relación» consideraba el episodio Ballesteros-Beretta (1963), p.123. En semejante dirección, las más recientes opiniones de Vivancos (1995), p. 82, nota 1, Gómez Redondo (1998), p. 1021-1022, Lappin (2002), p. 278-279 y García de la Borbolla (2003), p. 454-462.

5 . Es un honor recordar que Miguel Vivancos fue el primero en sugerirme que Pedro Marín pudiera no haber sido el autor de este cuarto milagro. Ténganse en cuenta las observaciones de Karl-Heinz Anton (1988), pp. 17-18.
} 
No parecen en efecto existir razones que pongan en duda los presupuestos fundamentales sobre los que se ha venido basando el estudio de este cuarto milagro de los Miraculos romançados, es decir,

1. que Pero Marín se hallaba presente en el monasterio de Silos en el momento en que tuvo lugar la aparición de santo Domingo a Alfonso X; en el texto se lee cómo, tras la aparición del santo, ${ }^{6}$ el monarca pidió que un monje cantase junto a las santas reliquias la misa de reyes en acción de gracias: «Et la missa fe cantada XXVII dias \& cantola Pero marín monge del monasterio ». ${ }^{7}$

2. que el propio Pero Marín fue el autor del milagro 4, como lo fue de la colección. De ello parece dar fe el epígrafe que da título a la obra según dos de los tres manuscritos que han llegado hasta nosotros : «Estos son los miraculos romançados como saco santo Domingo los cativos de captividad y fizo los escrevir Pero Marín monge del monesterio».8

3. que el motivo que llevó al autor del texto a presentar una imagen positiva del rey bienhechor del monasterio fue el agradecer públicamente la donación de una importante martiniega a los monjes por parte de Alfonso X. ${ }^{9}$

Las conclusiones del presente trabajo no modificarán sustancialmente el segundo y tercero de estos presupuestos, ${ }^{10}$ aunque acaso sí alteren el primero. Comencemos asumiendo que Pero Marín

\footnotetext{
${ }^{6}$. Anton (1988), p. 44: «Depues delos matines contra la mannana durmiendo el Rey aparesciol Santo Domingo en vision».

7. Anton (1988), p. 45.

${ }^{8}$. Anton (1988), p. 17.

${ }^{9}$. Así, García de la Borbolla (2003), especialmente p. 464: «[...] el hagiógrafo, muy consciente de la actitud benefactora de la monarquía, presenta a un monarca devoto y piadoso, cuyos gestos respondían a un profundo sentimiento religioso y a una arraigada espiritualidad cristiana». La martiniega es una renta pagada el día de san Martín, que en el caso que nos ocupa los habitantes de la villa de Silos satisfacían al rey y que Alfonso X otorgó al monasterio. Los habitantes de Silos habían pues de pagar a los monjes una cantidad sustancial (García de Valdeavellano, 1982, p. 251), en este caso de 375 maravedíes (véase infra).

${ }^{10}$. Para la función propagandística y de la construcción discursiva de este milagro, me permito remitir a Arizaleta, «La memoria del monarca» (en prensa).
} 
fue el autor o recopilador de esta colección de milagros; escritos en lengua vernácula como su título indica, ${ }^{11}$ los Miraculos romançados fueron "compuestos sistemáticamente", según Karl-Heinz Anton, en 1284 o $1285,{ }^{12}$ cuando fueron reunidos algunos textos preexistentes con otros, con el fin de formar una colección destinada a atraer peregrinos al monasterio de Silos. Al figurar en las primeras líneas del libro como autor («fizo los escrevir Pero Marín») — tenga este término el sentido de creador, recopilador o redactor, poco importa ahora mismo - , el monje Pero tomaba el relevo de aquellos que tras la muerte de santo Domingo habían consignado los milagros realizados por éste: Grimaldo, autor, a fines del siglo XI, de la Vita Dominici Silensis, ${ }^{13}$ y Gonzalo de Berceo, quien escribió, hacia 1236, la Vida de Santo Domingo de Silos a partir de la Vita Dominici. ${ }^{14}$

Los prodigios enumerados en los Miraculos romançados son los llevados a cabo por el santo desde 1232 hasta 1287, es decir dos siglos después de su muerte, ocurrida en $1073 .^{15}$ Dicho periodo podría coincidir en parte con el de la vida del propio Pero Marín, quien con seguridad fue monje y procurador del monasterio de Silos desde 1289 hasta al menos $1293 .{ }^{16}$ A fuer de su contenido, los Miraculos se inscribieron en la actualidad terrenal de Pero y de Silos, puesto que el asunto general de la obra (es decir, la acción de

\footnotetext{
11. Gómez Redondo (1998), p. 1022, afirma que la obra es «la primera muestra de una producción hagiográfica en prosa vernácula». No cabe ignorar el que los Miraculos romançados se redactaran en romance, cuando hagiógrafos peninsulares contemporáneos de Pero Marín como Rodrigo de Cerrato, Bernardo de Brihuega o Pedro Ferrando escribieron sus vitae en latín: cf. Henriet (2000), p.79-80; Baños (2003), p. 208-222.

12. Anton (1988), p. 20-34; p. 20. «De los 91 milagros, 51 (el 56\%) se refieren al año de 1285 , los restantes se reparten sobre un periodo de 55 años. Si se toma en cuenta el número de milagros que, según su relato correspondiente, fueron obrados entre 1280 y 1285 , se llega a 76 , es decir que un $83,5 \%$ de los sucesos referidos tienen lugar en un 11\% de la totalidad del espacio de tiempo» y p. 27: «La forma de los textos y el aspecto de la cronología [...] dan lugar a suponer como fecha de la composición sistemática de los textos los años 1284 o 1285, con inserción de textos preexistentes, con el propósito de reunirlos en un solo volumen».

13. Vivancos (2003), p. 224.

${ }^{14}$. Los Miraculos certifican las palabras de Gonzalo de Berceo en su Vida de Santo Domingo de Silos, estrofa 755 (Ruffinatto 1992, p. 447): «[...] de los sus miraglos los diezmos non avemos, / ca cada día crescen, por ojo lo veemos, / crecerán cutiano después que nos morremos».

${ }^{15}$. Vivancos (2003), p. 253-254

16. En cuanto a su labor como procurador del monasterio, Vivancos (1998), documentos 301, 309, 310, 316, 317.
} 
santo Domingo como liberador de cautivos) cobraba particular sentido en el contexto histórico de la segunda mitad del siglo XIII, caracterizado por el elevado número de cristianos hechos prisioneros en los enfrentamientos contra los benimerines. ${ }^{17}$ Los Miraculos romançados fueron pues concebidos como obra del presente del monasterio en el último cuarto del siglo XIII: la mejor prueba de ello es que más de la mitad de los relatos se refieren al año de 1285; el hecho narrado coincide por consiguiente con la composición de la narración. ${ }^{18}$

Se ha venido aceptando que esa misma actualidad pudo haber justificado el milagro 4 de la colección. Por su carga contextual - el santo dispone un final feliz para las tribulaciones de Alfonso X, al decidir su victoria sobre sus enemigos Lope Díaz de Haro y los reyes de Aragón y Navarra - , por inscribirse en un marco cronológico reconocible,$^{19}$ el milagro 4 comparte las características de la crónica, $\mathrm{y}$ es semejante en esto a los demás relatos de la colección. ${ }^{20}$ Mediante la participación de santo Domingo en los asuntos del monarca, el texto confirma la implicación de algunas figuras de

17. Gómez Redondo (1998), p. 1019 y Lappin (2002), p. 275 y p. 280-281: «Miraculous liberation was also linked [...] to the ideal or the idea of the conquest of Moorish lands [...]. Popular devotion to Dominic must have also contained this half-unspoken element, nebulous but discernable, that linked his specialization in the liberation of captives to his care for Christendom, both in maintaining its current boundaries and in enlarging them».

${ }^{18}$. Véase nota 12 , supra.

19. El texto precisa los días del año en que ocurrieron los hechos narrados, si bien parece que los copistas no hayan transmitido con absoluta fidelidad la información contenida en el original: donde hoy se lee «ERa de mil doscientos noventa y tres años. Lunes çinco días de noviembre» para fijar la llegada del rey Alfonso a Silos, habría que leer ' 12 de noviembre' o '15', según los datos históricos, la diplomática y el calendario; cf. Ballesteros-Beretta (1963), p. 123: «[...] Alfonso no llegó a Silos el 5 de noviembre, porque todavía se hallaba en Burgos, y el 5 de noviembre cayó en viernes. Hasta el 12 no se sabe de su estancia en Silos y precisamente el 15 fue un lunes. En consecuencia, pudo haber una confusión en el manuscrito y ser falta del copista que trasladó 5 por $15[\ldots]$ [.. Esos días de noviembre de 1255, pues, fueron el punto de partida del prodigio. Este debió de tener lugar entre el 18 y el 20 de noviembre de ese mismo año, puesto que santo Domingo se apareció al rey, según el texto, después de la oración de maitines en la noche del quinto día de su estancia en el monasterio. Ballesteros-Beretta, (idem) p. 124 : «Afirma que Alfonso estuvo cinco días en el convento en ese noviembre de 1255 y el Itinerario del monarca nos da siete, desde el 12 hasta el 18 [...]. Quizá la escena narrada por Marín pueda situarse en el 18, última fecha que tenemos respecto a la estancia del monarca en Santo Domingo de Silos»».

${ }^{20}$. Anton (1988), pp. 17-27, "Los Milagros (sic) romançados como crónica”. 
santidad en los asuntos temporales del reino, ${ }^{21}$ y permite asociar como señalábamos propaganda religiosa y propaganda política, pues en él se hace la glosa particular de una de las virtudes de santo Domingo de Silos, la de su capacidad de protección de la monarquía cristiana.

Contemporáneo de sucesos cruciales para el monasterio, Pero Marín aparece por lo tanto como el autor ideal del milagro 4, tanto más cuanto que el propio texto asegura como sabemos su presencia en el momento de lo narrado («la missa fe cantada XXVII dias \& cantola Pero marín»). No parecen existir razones para no creer en la veracidad de tal afirmación, que hace del monje Pero testigo del milagro e identifica autoridad y autoría: escribe quien vio; la realidad de lo sucedido ha de ser pues innegable. La legitimidad del autor-narrador no parece poder ser puesta en duda. ${ }^{22}$ Ahora bien, téngase en cuenta que es éste el único dato que permite suponer que Pero Marín se encontraba en Silos en 1255: de su presencia en el monasterio no hay noticia documental cierta hasta el 22 de febrero de 1289, cuando el abad y los monjes de Silos lo nombraron procurador en el conflicto entablado con los clérigos de San Pedro de la villa de Silos. ${ }^{23}$ Por supuesto, Pero pudo cantar la misa de reyes aquellos días de fines de 1255 , y desaparecer a continuación de la producción textual del monasterio durante 30 años, para resurgir en 1285-87 y encargarse de la redacción del milagro 4, así como del resto de la colección. Sin embargo, existe al menos otra posibilidad respecto de la autoría y fecha de redacción de este texto, a la que me referiré más abajo.

Volvamos al relato cuarto de los Miraculos, para detenernos en otro de los datos que proporciona: en él se dice que una narración del prodigio habría sido escrita en latín en Sevilla, por parte de un tal «ffrey Johan de los descalzos», poco después de que el monarca abandonase Silos en la primavera de 1256. El texto del milagro informa en efecto de la concesión al monasterio por parte de Alfonso $X$ de un privilegio real, dado en Calatañazor el 19 de febrero de 1256, así como de la ida del monarca a Sevilla y de la llegada a Silos de una versión latina de lo ocurrido «en el mes de junio», podemos suponer que del mismo año 1256:

\footnotetext{
${ }^{21}$. Henriet (2000).

${ }^{22}$. Anton (1988), p. 12 : « [...] del milagro 4 consta que en 1256 (sic) ya era monje de Silos ».

23. Cf. nota 16, supra. Sobre el conflicto entre el monasterio y el concejo de Silos, Escalona (2003) y Peña Pérez (2003).
} 
$\&$ mando que uos den della bon Priuillegio. $\&$ fue dado en Canatanaçor. \& dessa pressa fues el Rey pora Seuilla. \& quando y fue mando lamar a ffrey Johan delos descalços. \& dixol el Rey como passara todo este fecho con Santo Domingo. \& mandol escreuir este miraculo en latin. \& embiol el Rey seellado con su Seello aqui. Enel mes de Junio. ${ }^{24}$

¿Qué significa la alusión, en el relato romance, a una redacción latina ? Podríamos comprenderla como indicio de la existencia de dos narraciones contemporáneas de lo sucedido en Silos, si aceptamos los dos primeros presupuestos: Pero Marín se encontraba en el monasterio, fue testigo de lo sucedido y puso por escrito el prodigio. Una de estas narraciones sería sevillana, compuesta en la primavera de 1256 , y por lo tanto inmediata a la resolución del conflicto evocado en el texto; la otra sería silense, quizá compuesta poco después de junio de 1256. Si esta suposición fuera cierta, dos autores, Juan y Pero, habrían ejercido de propagandistas, el primero directamente para el monarca, bajo cuya autoridad habría colocado su escritura, el segundo también para el rey Alfonso, aun si básicamente el contenido del milagro 4 hace la apología de las ventajas obtenida por el monasterio en 1255.

De la identidad de 'Juan de los descalzos' no sabemos nada, salvo que posiblemente fuera un franciscano. ${ }^{25}$ Fácil sería caer en la tentación de identificarlo con un Juan, calígrafo de Alfonso X en Sevilla en los años que nos interesan, ${ }^{26}$ pero es preferible mantener la prudencia en este punto. La existencia de su relato latino (existencia acaso quimérica puesto que de ella no queda más que la afirmación del autor del milagro 4$)^{27}$ resultaría entonces ser el fruto de la

\footnotetext{
${ }^{24}$. Anton (1988), p. 46.

25. Agradezco tanto a Miguel Vivancos como a Julio Escalona sus indicaciones respecto de esta cuestión.

${ }^{26}$. Galván Freile (2001), p. 41-42, comenta la actuación del calígrafo Juan González en la composición de unos de los manuscritos de las Cantigas de Santa María, el ms. Escorial B.I.i, y añade p. 42 : «Parece claro, pues, que en la ciudad de Sevilla se creó un importante taller de copia e iluminación de manuscritos [...] taller, o talleres, vinculados directamente al soberano, a las obras emprendidas por él mismo y con un carácter completamente independiente con respecto a los centros monásticos, que hasta este momento habían sido los productores de códices iluminados».

${ }^{27}$. El texto en latín no se encuentra entre los editados por Vivancos (1995); tampoco en el Diplomatario andaluz editado por González Jiménez (1991).
} 
voluntad de Alfonso X de dejar memoria del prodigio acaecido en Silos. El que la inventio del relato recayera en Alfonso justificaría la focalización en la figura del monarca y encajarían así el alcance laudatorio del texto $\mathrm{y}$ su función política como sustento propagandístico de un inicio de reinado. El soberano sería pues el propietario intelectual del milagro 4 , al mandar escribir una historia en su provecho y para publicidad de su capacidad de represión de los «principes», es decir, de los ricoshombres y monarcas vecinos. Si el instigador de lo narrado fue Alfonso X, Juan y Pero fueron entonces autores por procuración, encargados de probar mediante su arte de la escritura el poder del soberano $\mathrm{y}$, accesoriamente, su respectiva maestría clerical. Lo que es más, el monje Pero completaría estas dos funciones con su trabajo de publicista de las aspiraciones del monasterio de Silos.

Ahora bien, ¿ cuál es la naturaleza del relato cuarto de los Miraculos romançados? Cabe la posibilidad de que se tratase de un texto autónomo, concebido independientemente de cualquier otro, pero más verosímil resulta la hipótesis de que este milagro en lengua vernácula fuese la traducción de ese hipotético texto latino de Juan. $\mathrm{Su}$ autor se habría entregado en ese caso a una labor de reescritura (cuyas modalidades son imposibles de verificar), silenciando su relación con su fuente latina, puesto que en ningún momento se refiere explicitamente a ella, y añadiendo marcas propias de autoridad y legitimación, tales como la presencia de Pero Marín en el lugar y día de la aparición de santo Domingo, que enraizaban la narración en Silos y circunscribían la breve alusión al texto latino a una señal de autoridad cierta, pero también relativa, por ser ajena al monasterio. Tal maniobra delimitaría los espacios de poder: la autoridad monárquica subyacente en el texto latino virtual permanecería presente en el milagro 4 pero, creo, se desvanecería un tanto por haberse transmutado el relato de Juan, clérigo en Sevilla a las órdenes de Alfonso X, en el relato de un monje en Silos a todas luces consciente de la necesidad de obrar por los intereses del monasterio.

Y ahora conviene retomar la cuestión a la que se ha respondido parcialmente: $i$ tuvo el texto 4 de los Miraculos romançados otra función que la de hacer la propaganda de Alfonso $\mathrm{X}$ ? Las pruebas palpables de lo sucedido en el scriptorium silense en la segunda mitad del XIII no existen en el caso que nos ocupa, pero sí sería posible intentar extraer algún tipo de conclusión sobre el o los objetivos del milagro a partir de la forma y la estructura de los Miraculos romançados. A sabiendas de la fragilidad de las consideraciones que siguen y de su carácter provisional, se puede avanzar que el milagro 4 representa un caso aislado en la colección 
hagiográfica de la que nos estamos ocupando por diversas razones. En primer lugar, por su temática: en los restantes relatos del libro se expone variadamente la capacidad del santo para liberar cautivos y, en menor medida, sanar enfermos. ${ }^{28}$ Sólo en el milagro 4 la intervención de santo Domingo es de naturaleza marcadamente política. En segundo lugar, por constituir el cenit del bloque inicial de los Miraculos, construidos en torno a la figura de Alfonso X y por aparecer, de tal modo, como el punto de inflexión de la demostración del poder monárquico sustentado por el poder monástico. En tercer lugar, por su carácter 'literario', es decir, por el hábil empleo del diálogo, de las técnicas creadoras de suspense, o de la descripción, por parte de su autor. ${ }^{29}$ También se destaca el milagro 4 por su longitud, siendo con mucho el más amplio de la colección, ${ }^{30}$ lo cual indica el interés que el tratamiento del episodio debió de representar para quien lo compusiera. Por fin, y sin desarrollar aquí este aspecto, es igualmente excepcional este relato dentro de los Miraculos por el gran número de marcas de autoridad que contiene.

Es pues la narración que nos ocupa un caso único en la obra. La razón de semejante especificidad probablemente sea, como se ha venido sosteniendo, su función como documento de propaganda monárquica consustancial al hecho que el monasterio de Silos estuviera sujeto al patronato regio. Por supuesto, también se explica su originalidad por el inmenso valor que la narración de los hechos, fingidos o reales, representaba para las ambiciones de la propia abadía. Pero quizá exista todavía otra causa que justifique la presencia en los Miraculos de un texto tan diferente del resto de los milagros recopilados, que en múltiples ocasiones no son sino una repetición casi literal unos de otros.

\footnotetext{
28. En cuanto a la liberación de cautivos, ver Lappin (2002), p. 275: 71 relatos de 91 cuentan cómo prisioneros escaparon (66 de manos de moros, 5 de manos de ministros de la justicia) gracias a la intervención de Santo Domingo. La veintena restante trata de curaciones obradas por el santo y de prodigios en relación con las reliquias de éste o con los rebaños del monasterio. Gonzalo de Berceo escribía, al dirigirse al santo en su Vida de Santo Domingo de Silos, estrofa 773: «Ruega por los enfermos, gánalis sanidad / piensa de los captivos, gánalis enguadad / [...] que tenga a derecho su ley la christiandad» (Ruffinatto, 1992, p. 453). Respecto de la invocación de santo Domingo de Silos como abogado de felices partos, ignorada por los hagiógrafos medievales, Vivancos (2003), p. 261-262.

29. De estos tres primeros puntos me ocupo detalladamente en Arizaleta, «La memoria del monarca» (en prensa).

30. Ocupa el milagro 4 en la edición de Anton (1988) 140 líneas, mientras que la longitud media de los restantes relatos (con algunas excepciones) es de 35 líneas.
} 
Ya se ha dicho más arriba, los Miraculos romançados fueron compuestos en la forma que conocemos hoy alrededor de 1285. Es por consiguiente verosímil (si no forzosamente cierto), que el milagro 4 de la obra también hubiese sido pensado como componente clave de una colección que cobraría sentido pleno a fines del siglo XIII, reinando en Castilla y León no ya Alfonso X, sino su hijo Sancho IV. El relato de la aparición de santo Domingo al soberano debió de ser pues redactado en 1285-1287: como la obra entera, el texto que nos interesa se enmarca en la actualidad de dichos años, «cuando la trifulca con el concejo de Silos estaba en pleno ascenso», ${ }^{31}$ al fijar por escrito nada menos que la transferencia de la renta, que la villa de Silos pagaba al monarca, al monasterio. El texto no puede ser más claro :

[...] dixol (el rey Alfonso). abbat mucho bien \& e mucha merçet me ha fecho el nuestro ssennor iesu Cristo. por ruego de Santo Domingo. \& pedit me un don qual quisierdes $\&$ dar uos loe. El abbat ueno luego a Cabildo $\&$ mostro lo al Conuento. \& acordaron quel pidiessen la martiniega que el auya enla villa $\&$ entanto que aurian toda la villa ala merçet del monesterio fizieron esta petiçion $[\ldots] \&$ el rey leyola \& riose. \& dixo abbat. non queredes que aya yo nada en esta villa. mas otorgo uos la \& sola auos \& $\&$ al Conuento por yuro de heredat pora siempre iamas. ${ }^{32}$

Como se ha señalado repetidamente, esta narración hagiográfica tiene un clarísimo objetivo en la política local de Silos, al establecer el dominio del monasterio sobre su acérrimo rival, el concejo: "aurian toda la villa ala merçet del monesterio". Y por el camino de la reivindicación monástica llegamos al testimonio de Pero Marín. El hilo que pudiera unir a este monje con Silos en el año de 1255 es tenue, lo hemos visto. Bien pudiera ser que Pero Marín no hubiera participado en la vida del monasterio sino a partir de la década de 1280 , cuando habría demostrado su habilidad para los asuntos judiciales y escriturarios, ganando así su nombramiento como procurador, y su renombre como autor de una colección hagiográfica, los Miraculos, concebida en ese fin de siglo para

\footnotetext{
${ }^{31}$. Escalona (en prensa).

${ }^{32}$. Anton (1998), p. 45.
} 
ampliar la gloria (y los bienes) del monasterio. ${ }^{33}$ En tal caso, la mención a Pero en el milagro 4 sería un elemento inventado...que falsearía mínimamente el contenido de dicho relato y que, ante todo, garantizaría la veracidad de lo narrado. Lo que es más, certificaría esa pequeña patraña que el relato era propiedad de su autor, quien sin duda fue, alrededor de 1285, Pero Marín. Con esto quiero decir que Pero debió hacerse cargo de la composición del texto, incluso si ordenó a un copista - como sugieren las palabras "fizo los escrevir" - poner por escrito la narración por él pergeñada y marcada con el sello de su presencia y de su autoridad. Pero Marín, autor del milagro 4, aumentó el texto original (i latino ? ¿ esbozado en 1256 ?), si lo hubo, mediante un suplemento de sentido que establecía a las claras su función como agente y transmisor de la memoria de las grandes horas del monasterio. ${ }^{34}$ Pudo delegar la escritura de la narración de su actuación memorable, o pudo escribirla él mismo, poniendo de relieve su competencia y al mismo tiempo construyendo la memoria del monasterio: la memoria de Silos se confundió a fines del XIII con la memoria de Pero Marín. Porque la voz del joven monje elevándose en acción de gracias atribuye el milagro 4 a Pero, al significar la impronta de su autoridad, y porque de tal manera los Miraculos están marcados por la huella inicial de Pero Marín, que tuvo un lugar fundamental en la construcción memorial del monasterio. En este proceso de conmemoración política y hagiográfica, al igual que los Miraculos romançados, debieron de participar otros muchos textos, entre los cuales se encuentran un par de privilegios reales, en los que quiero detenerme brevemente a continuación.

\section{LOS PRIVILEGIOS REALES}

Por si quedara alguna duda acerca del carácter de caja china del milagro 4 de los Miraculos romançados, recordemos que este texto no sólo alude a otro latino más o menos fantasmagórico, sino que también se refiere su autor al privilegio dado en Calatañazor por Alfonso X en febrero de 1256:

$\&$ mando que uos den della bon Priuillegio.

\& fue dado en Canatanaçor.

\footnotetext{
33. A tal renombre se debe sin duda el que Pero Marín sea mencionado en el milagro «que un autor desconocido añade al último de la colección original y que se refiere al año de 1287 », Anton (1988), p. 12.

34. Parafraseo a Baumgartner (2001), p. 391 : el autor es «celui qui ajoute un supplément de matière et de sens, d'interprétation, au texte qui lui sert de source et support et [et qui est] garant d'un texte latin qui fait autorité pour le temps présent».
} 
Alusiones, hechos y textos parecen encadenarse a la perfección, si atendemos a las siguientes palabras:

[...] entiendo que el nuestro Sennor me faze mucho de bien e mucha de mercet por la devoción que yo he en el sancto cuerpo de Sancto Domingo que iaz en aquel mismo logar, do e otorgo a uos, don Rodrigo, abbat de santo Domingo de Silos, e a todos los uestros succesores que despues de uos uernan e al monasterio desse mismo logar, tan bien a los que agora hy son como a los que seran d'aqui adelant pora siempre iamas, los tresçientos e setaenta e cinco moraudis que yo he por marcatga cad'anno en esa misma villa de Sancto Domingo, que los ayades libres e quitos por iuro de heredat para siempre iamas. E mando a quantos esta marcatga sobredicha cogieren, quier por mi, quier por cuantos regnaren depues de mi en Castiella e en Leon, que d'aqui adelante que recudant con ella al abbat e al monasterio sobredicho. ${ }^{35}$

Éste sería un fragmento del privilegio que el rey Alfonso dio al monasterio, donación anunciada por el texto hagiográfico. Nada más natural que la existencia real y concreta de ese privilegio escrito, imperiosamente necesitado por los monjes como sanción de la martiniega de 375 maravedíes, que confirmaba el poder de la abadía y suponía la encarnación de la virtud política de su santo patrón. Ahora bien, no ha llegado hasta nosotros el texto de ese documento de 1256, sino el de la confirmación del mismo, dada en 1287 y por el sucesor de Alfonso: ${ }^{36}$ el 30 de marzo de 1287 Sancho IV confirma en el privilegio de la martiniega concedido por su padre, donde se transcribe el documento de 1256 :

[...] queremos que sepan por este nuestro priuilegio los que agora son e seran daqui adelante, commo nos, don Sancho, por la gracia de Dios rey de Castilla, de Toledo, de

\footnotetext{
${ }^{35}$. El privilegio en romance está editado en Vivancos (1995), doc. 205, p. 82-85.

${ }^{36}$. Escalona (en prensa) : «El "buen privilegio" que Alfonso X promete dar al abad no es otro que el documento de 1256 [...] y cuyo original no se conserva, sino que el primer testimonio es su confirmación por Sancho IV en 1287».
} 
Leon, de Gallizia, de Seuilla, de Cordoua, de Murcia, de Iahen e del Algarue, viemos un priuilegio del rey don Alfonsso, nuestro padre, que Dios perdone, fecho en esta guisa [sigue el privilegio de 1256] E nos, sobredicho rey don Sancho, regnant en uno con la reyna donna Maria, mi mugier, e con nuestros fiios el inffante don Fernando, primero e heredero, et con don Alfonsso, en Castilla, en Toledo, en Leon, en Gallizia, en Seuilla, en Cordoua, en Murcia, en Iahen, en Baça, en Badalloz e en el Algarue, otorgamos este priuilegio $\mathrm{e}$ confirmamoslo e mandamos que uala asi como uallio en tiempo del rey don Alffonso, nuestro padre. $^{37}$

Este privilegio de 1287 corrobora la posterioridad del don otorgado por Alfonso 30 años antes, y contribuye a legitimar el linaje real al permitir a Sancho IV manifestarse públicamente como heredero de Alfonso, "nuestro padre, que Dios perdone". Y lo que es verdaderamente pertinente para este estudio, coincide en el tiempo con la redacción de los Miraculos romançados y plantea la existencia de una red de textos afines en su cronología y posiblemente en su objetivo: el privilegio de 1256 es exactamente contemporáneo del texto latino de fray Juan. Ambos textos pudieron no haber existido: ya hemos hablado del hipotético relato latino y, si creemos a Julio Escalona, estaremos de acuerdo en considerar ese privilegio de 1256 como 'sospechoso'. Nos hallaríamos pues ante dos creaciones espurias, coetáneas de la llegada de Alfonso al monasterio. En cuanto a la confirmación de 1287, es contemporánea de los Miraculos y por tanto del texto 4. Por último, los Miraculos romançados habrían sido compuestos más o menos en los años en que se añadieron algunas piezas falsas, o de dudosa veracidad, al Cartulario Gótico de Silos, que hemos de traer a colación porque, precisamente, una de esas piezas añadidas fue el presunto privilegio de 1256.

El Cartulario Gótico fue compuesto en dos fases: la primera estaba terminada después de 1255 , la segunda hacia $1283 .^{38} \mathrm{El}$ bloque original de este libro estaba constituido por privilegios confirmatorios dados por Alfonso X a Silos en 1255. En 1283 se le añadió una continuación, y se le antepuso un cuaderno que se

\footnotetext{
37. Vivancos (1995), doc. 292, pp. 207-210, p. 208.

${ }^{38}$. Sobre el Cartulario Gótico de Silos, ver por el momento Lera (2003).
} 
iniciaba con la falsa carta fundacional de Fernán González, ${ }^{39}$ y proseguía con una serie de privilegios falsos o sospechosos, entre los cuales se hallaba ese privilegio supuestamente dado en Calatañazor. Las piezas en cuestión son las siguientes: $:^{40}$ Privilegio del Cuende Fernan Gonçalvez que nos dio la villa e es seellado con seello de çera, más transcripción de la confirmación por Alfonso X en 1255 del diploma falso por el que Fernán González fundó el monasterio de 919; Privilegio del emperador don Alfonso que nos otorgó la villa e el termino et es seellado con çera, más transcripción de la confirmación por Alfonso X en 1255 del documento por el que Alfonso VII en 1155 definió el coto jurisdiccional del monasterio; Privilegio del rey don Alfonso fijo del rey don Ferrando que nos dio toda la marçatga (sic) de la villa de Sancto Domingo et es seellado con plomo, más transcripción del documento sospechoso de 1256 por el que Alfonso X dio al monasterio la martiniega regia en la villa de Silos; Privilegio del Emperador don Alfonso que nos mando poblar la villa de Silos, más transcripción de la confirmación por Alfonso X en 1255 del documento falso por el cual Alfonso VI dio a Santo Domingo de Silos licentia populandi dentro de su término.

Mi ignorancia me impide ir muy lejos en mi análisis, pero a la vista de esta información podemos constatar las analogías siguientes entre los textos (reales o no) que han sido objeto de este estudio: los textos de 1256, es decir la narración latina y el privilegio (i también en latín ?), si existieron, no han llegado hasta nosotros ; los textos de 1287, es decir los Miraculos romançados y la confirmación de Sancho IV, existen palpablemente y constituyen la puesta por escrito definitiva, clara y pública (incluso si no salieron del scriptorium silense) del entramado de 'mercedes' en el que se fundamenta el poder monástico y el poder monárquico: santo Domingo favorece a Alfonso quien favorece al monasterio...el cual favorece al rey doblemente, al facilitarle el contacto con su santo patrón y al disponer de escribanos hábiles, dispuestos a ejercer una propaganda común.

De estas analogías acaso se puedan extraer algunas conclusiones: el texto presuntamente más vinculado a los sucesos de 1255 contiene una información probablemente falsa, debida a la voluntad de Pero Marín en los años 1280. El Cartulario Gótico es en parte fruto de una mistificación que tuvo lugar en 1283. Los Miraculos y el Cartulario aseguran a su manera la supremacía del

\footnotetext{
39. Ver Escalona (2003).

. Sigo en todo a Escalona (2003), quien enumera y analiza las rúbricas de cuatro de los cinco documentos de ese cuaderno inicial.
} 
monasterio, mediante la invención de una arqueología favorable a las ambiciones de la abadía o gracias a la ficcion de los poderes de santo Domingo, siempre por supuesto favorables a sus hermanos. Bajo formas diferentes, la propaganda es idéntica. Nada más 'normal' que esta operación monástica de falsificación. ${ }^{41}$ Ahora bien, si abandonamos las conclusiones para internarnos en el terreno resbaladizo de las deducciones (destinadas por supuesto a ser corregidas), podríamos sugerir lo siguiente: puesto que Pero Marín actuó en los últimos años del siglo XIII como el hagiógrafo de Silos, y también como su representante legal, ¿ no sería concebible que tras la doble empresa de falseamiento que nos ha interesado, más visible en el caso del Cartulario que en el de los Miraculos, y sin embargo comparable, se hubiese hallado el propio Pero ? No parece ahora haber lugar a duda respecto de su papel en la particular recopilación de la colección de milagros, y resulta verosímil, creo, que este monje de Silos se hubiera encargado de organizar la más compleja operación de impostura materializada en el cartulario. Ambas obras se caracterizan por dejar campo abierto a la representación de la realeza y a la apología del monarca ${ }^{42}$ y encarnan la alianza entre el monasterio de Silos y los reyes castellanos en la segunda mitad del siglo XIII. La convivencia textual de los intereses monásticos y monárquicos es una constante de los Miráculos, también del Cartulario... pudiera, bien pudiera haber sido Pero Marín la mano oculta del affaire de Silos.

En este juego de alianzas concede en apariencia Pero Marín, al menos en el milagro 4, la ventaja a la monarquía en cuanto a las pruebas de autoridad, política y escrituraria ("embiol el Rey seellado con su Seello"), ${ }^{43}$ pero conserva en realidad la más ostensible de las marcas de propiedad, aquella que afirma su presencia (falsa) en el espacio del monasterio y en el espacio del texto. Si la narración de la actuación del soberano legitima la falsificación, la autoridad monárquica es suplantada por la autoridad del escribano, quien posee el poder de recrear un espacio de memoria para el monasterio,

\footnotetext{
${ }^{41}$. Ver Kölzer (2001).

${ }^{42}$. No hay espacio aquí para detenernos en el protocolo inicial de la confirmación de Sancho IV, harto interesante a este respecto aun siendo un elemento estereotipado, ni para comentar la representación de la figura de Alfonso x en los Miraculos romançados. Ver para este último punto Arizaleta, «La memoria del monarca» (en prensa).

${ }^{43}$. Fraenkel (2001), p. 422-23, los sellos «marque[nt] à un niveau plus métaphorique la fermeture du texte : l'acte est rédigé, il a été vérifié, il est enfin scellé. Les sceaux servent aussi à affirmer la propriété sur des objets. Ainsi marqués, les objets témoignent du droit que leurs possesseurs ont sur eux».
} 
en donde se imponga el carisma de su figura de señor de lo escrito, de autor insoslayable, de protagonista de la construcción memorial de Silos.

Dudo ahora de que estas páginas convenzan. En el peor de los casos, espero que sirvan para fijar la alargada sombra de nuestro Pero Marín, a quien se le atribuía siglos después de su paso por el monasterio de Silos un 'libro de sermones en romance dirigido a la excelencia del conde de Haro', sermones cuyo autor había sido, en verdad, Vicente Ferrer. ${ }^{44}$ Falsario o entusiasta transmisor de la memoria de Silos, Pero Marín había logrado permanecer en la memoria al asociarse con la monarquía.

${ }^{44}$. Cátedra (1990), p. 44-46. 
BIBLIOGRAFIA

ANTON, Karl-Heinz, ed. (1988). Los « Miraculos romançados » de Pero Marín. Edición crítica, introducción e índices, Burgos, Abadía de Silos.

ARIZAlETA, Amaia (en prensa). " La memoria del monarca: Alfonso X, testigo de Pero Marín (Miraculos romançados, 4) », Cahiers d'Etudes Médiévales Hispaniques.

BAllesteros-Beretta, Antonio (1963). Alfonso X el Sabio, Madrid, Salvat.

BAUMGARTNER, Emmanuèle (2001). « Sur quelques constantes et variations de l'image de l'écrivain (XII-XIII siècle)», en Auctor \& auctoritas. Invention et conformisme dans l'écriture médiévale, ed. M. Zimmermann, Paris, Ecole des Chartes, pp. 391-400.

CATEDRA, Pedro M. (1990). Los sermones atribuidos a Pedro Marín, Salamanca, Universidad.

ESCALONA, Julio (2002). « Los nobles contra su rey. Argumentos y motivaciones de la insubordinación nobiliaria de 1272-73», Cahiers de linguistique et de civilisation hispaniques médiévales, 25, pp. 131-162.

ESCALONA, Julio (2003). « Lucha política y escritura. Falsedad y autenticidad documental en el conflicto entre el Monasterio de Santo Domingo y el burgo de Silos (ss.XIII-XIV) », en Conflictos sociales, políticos e intelectuales en la España de los siglos XIV y XV. Actas de la XIV Semana de Estudios Medievales de Nájera, coord. José Ignacio de la Iglesia Duarte, Instituto de Estudios Riojanos, pp. 205-252.

ESCAlONA, Julio, AZCARATe, Pilar, LARrañAgA, Miguel (2001). « De la crítica diplomática a la ideología política. Los diplomas fundacionales de San Pedro de Arlanza y la construcción de una identidad para la Castilla medieval », en Actas del VI Congreso Internacional de Historia de la Cultura Escrita, ed. C. Sáez, vol. 2, Alcalá de Henares, pp. 159206.

FRAENKEL, Béatrice (2001). "L'auteur et ses signes», en Auctor \& auctoritas. Invention et conformisme dans l'écriture médiévale, ed. M. Zimmermann, Paris, Ecole des Chartes, pp. 413-427.

GALVÁN FREILE, Fernando (2001). « La producción de manuscritos iluminados en la Edad Media y su vinculación a las monarquías hispanas », Anuario del Departamento de Historia y Teoría del Arte, 13 , pp. $37-50$

GARCiA DE LA BORBOlla, Angeles (2003). « Santo Domingo de Silos en el siglo XIII: un Santo, una Abadía,un Rey », en Silos. Un Milenio. Actas del Congreso Internacional sobre la Abadía de Santo Domingo de Silos. I: Espiritualidad, ed. J.A. Fernández Flórez, Santo Domingo de Silos, Universidad de Burgos-Abadía de Silos, pp. 449-464. 
GÓMEZ REDONDO, Fernando (1998). Historia de la prosa medieval castellana. I. La creación del discurso prosístico: el entramado cortesano, Madrid, Cátedra, pp. 1021-1022.

GONZALEZ JIMENEZ, Manuel, ed. (1991). Diplomatario andaluz de Alfonso $X$, El Monte, Caja de Huelva y Sevilla.

KÖLZER, Theo (2001). «Le faussaire au travail», en Auctor \& auctoritas. Invention et conformisme dans l'écriture médiévale, ed. $\mathrm{M}$. Zimmermann, Paris, Ecole des Chartes, pp. 477-485.

LAPPIN, Anthony (2002). The Medieval Cult of Saint Dominic of Silos, Leeds, Maney Publishing.

LERA MAÍllo, José Carlos de (2003). « Noticia descriptiva del cartulario gótico del monasterio de Silos. Ms. $119 »$, en Silos. Un milenio. Actas del Congreso Internacional sobre la Abadía de Santo Domingo de Silos. II. Historia, ed. J.A. Fernández Flórez, Santo Domingo de Silos, Universidad de Burgos-Abadía de Silos, pp.521-540.

PEÑA PÉREZ, F. Javier (2003). « Las paradojas de la vida monástica en la Edad Media. Silos », en Silos. Un milenio. Actas del Congreso Internacional sobre la Abadía de Santo Domingo de Silos. II. Historia, ed. J.A. Fernández Flórez, Santo Domingo de Silos, Universidad de Burgos-Abadía de Silos pp.265-295.

VIVAnCos, Miguel C. (1995). Documentación del monasterio de Santo Domingo de Silos (1255-1300), Santo Domingo de Silos, Abadía de Silos.

VIVAncos, Miguel C. (1998). Documentación del monasterio de Santo Domingo de Silos. Indices 954-1300. Fondo antiguo de Silos. Fondo de Silos en el Archivo Histórico Nacional, Santo Domingo de Silos, Abadía de Silos. 